\title{
Design Development of Lightweight Disc Brake for Regenerative Braking - Finite Element Analysis
}

\author{
S. Sarip, Member, IACSIT
}

\begin{abstract}
The automotive industry has for many years identified weight reduction as a way of improving product competitiveness and thus the ability to make profits. One area that has been examined for weight reduction is vehicle with regenerative braking system (RBS). The greatest advantages of electric vehicles (EVs), and hybrid electric vehicles (HEVs) is their ability to recover significant amounts of braking energy using a RBS. Regenerative braking is an effective method to extend brake disc life, minimise disc rotor weight, minimise brake pad wear and to extend the working range of an EV or HEV. Regenerative braking would extend the working range of an EV or HEV provided that any extra energy consumption e.g. from increased vehicle mass and system losses did not outweigh the saving from energy recuperation, also reduce duty levels on the brakes themselves, giving advantages including extended brake rotor and friction material life, but more importantly reduced brake mass, minimise brake pad wear. The objective of this research is to define thermal performance on lightweight disc brake models. Thermal performance was a key factor which was studied using the 3D model in Finite Element Analysis simulations. Ultimately a design method for lightweight brakes suitable for use on any car-sized hybrid vehicle was used from previous analysis. The design requirement, including reducing the thickness, would affect the temperature distribution and increase stress at the critical area. Based on the relationship obtained between rotor weight, thickness, undercut effect and offset between hat and friction ring, criteria have been established for designing lightweight brake discs in a vehicle with regenerative braking.
\end{abstract}

Index Terms-Road vehicle, regenerative braking, simulation, lightweight, brake disc, design, thermal, temperature.

\section{INTRODUCTION}

It has been estimated that up to $70 \%$ of the kinetic energy of a passenger car could be dissipated through the friction brakes and the other (up to) $30 \%$ of the energy could be recuperated e.g. in the form of electrical power [1]-[2]. The need for conversion from kinetic energy to thermal energy by friction brakes therefore will decrease once regenerative braking is present in the system. The rest of the energy can be converted e.g. to electrical energy via a motor/generator $(\mathrm{M} / \mathrm{G})$. For a car with regenerative braking under a single stop braking event, where the energy dissipated via the front disc brakes is estimated as $70 \%$ of the total kinetic energy.

The automotive industry has for many years identified

Manuscript received October 9, 2012; revised December 4, 2012. This work was supported in part by the UTM Razak School of Engineering and Advanced Technology under Grant 4J079.

S. Sarip is with UTM Razak School of Engineering and Advanced Technology, UTM Kuala Lumpur, Jalan Semarak, 54100, K.L, Malaysia. (e-mail: shamsul@ic.utm.my). weight reduction as a way of improving product competitiveness and thus achieving commercial success. To achieve reduction in weight, components made of materials such as iron and steel can be replaced with re-designed components made of lighter materials such as polymers and aluminium. One area that has been examined for weight reduction is the brake system, e.g. aluminium and associated composite materials such as 'metal matrix composites' (MMC) for brake rotors have been studied extensively. Although aluminium is increasingly used in modern brake components, the frictional and thermal requirements of a modern automotive brake have limited its use for brake discs [3]. Friction brakes get hot when used and the heat energy is dissipated by forced convection, conduction and radiation from the exposed surfaces of the brake. Over-heating can cause malfunction of the braking system and present a safety hazard. Much theoretical work has been done to calculate accurately the temperature rise during braking for different speeds and designs of brake discs. [3]-[8] so the extent of the thermal loading on brake discs (rotors) is well-known.

Disc brakes are widely used on cars because of their better heat dissipation ability; a direct result of the exposed friction surface. The friction surface of a drum brake is inside and heat dissipation relies upon heat being conducted through the drum so car manufacturers fit drum brakes only on the rear axle of "low" performance cars. Additionally a drum brake provides a very effective parking brake. In commercial vehicles, drum brakes are still widely used across the world, being robust, durable and easy to maintain but in Europe most heavy goods vehicles now use disc brakes [9]. Furthermore, the performance requirement is not just for one isolated brake application, but for a series of high deceleration brake applications which form the part of the performance assessment known as the 'fade' test. So, the front brakes of a typical passenger car have to be designed to provide large amounts of braking torque, and withstand large amounts of heat generated, heat transfer, high temperatures and thermal loading. The size (and weight) of a car's disc brake therefore depends upon the performance required, specifically the braking torque, energy dissipation and power. It is possible to generate high braking torque from a smaller brake, but the energy and power involved may overload the brake and cause physical damage. Lightweight disc brakes (smaller in size using lighter materials designed for lower duty) have potential for passenger cars with regenerative braking. Regenerative braking is a feature of a hybrid and pure electric power train to recoup some of the energy dissipated during braking [10]. EVs and HEVs have the ability to recover significant amounts of braking energy using the electrical part of the power train as a RBS. However, even 
with regenerative braking, friction brakes are required to provide the necessary high duty braking performance, e.g. in the event of an emergency stop being required. Regenerative braking therefore has to work alongside a conventional friction system because the braking power in an emergency is too high for a purely electrical regenerative system: this is primarily due to the limited energy transfer rate of electrical energy storage devices. Regenerative braking does however take work off the friction brakes of a vehicle, thereby extending brake disc life, minimising disc rotor weight, minimising brake pad wear and extending the working range of an EV or HEV.

Regenerative braking in an EV cannot be used when the batteries are fully charged, or when the battery is at a high temperature because this could damage the battery. At low vehicle speeds regenerative braking could generate high braking torque causing vehicle instability (if a continuously variable transmission (CVT) is used to keep the M/G at its optimum operating speed); this need to be carefully controlled to avoid poor braking 'feel'. Braking energy recuperation for hybrid vehicles has been investigated by Ehsani et al., [2] using computer simulation to analyse the relationship between the recuperated braking energy from front wheels to the total braking energy available in a typical urban driving cycle. The results showed that $50 \%-60 \%$ of braking energy could be recovered by regenerative braking in urban driving. Regenerative braking can recover about $45 \%$ of total kinetic energy for a city bus [11].

\section{Finite ELEMENT ANALYSIS}

\section{A. Standard Ventilated Disc Vs. Prototype Disc}

For the work presented here, a test car has been used to investigate duty levels and braking performance. Legislation requires that the car can decelerate to rest at a minimum of $6.43 \mathrm{~m} / \mathrm{s}^{2}$ or $0.66 \mathrm{~g}$ from speeds up to $100 \mathrm{~km} / \mathrm{h}$ (vehicles of category M1-cars) although manufacturers' own specifications often far exceed this. For a Type 0 test on this particular car, with the engine disconnected (as defined in Regulation $13 \mathrm{H}$, Annex 4), the total kinetic energy to be dissipated by each front brake is $231 \mathrm{~kJ}$. The axle brake torque for each front brake is $1154 \mathrm{Nm}$ providing a brake force $(\mathrm{FB})$ of $3845 \mathrm{~N}$. The vehicle stops from $100 \mathrm{~km} / \mathrm{h}$ in 4.3 seconds and develops an initial braking power of $107 \mathrm{~kW}$. The simulation wheel rotational speed was set to $93 \mathrm{rad} / \mathrm{s}$ equivalent to $100 \mathrm{~km} / \mathrm{h}$ for single stop braking with the initial disc temperature at $20^{\circ} \mathrm{C}$. Heat was generated by pressing each pad on the disc with a uniform pressure of $6 \mathrm{MPa}$ on the piston which created a rapid temperature rise in the disc; in an actual car this would be approximately equivalent to a $60 \% \mathrm{~g}$ deceleration. For the drag braking, loading and boundary conditions were set to represent a constant wheel rotational speed of $28.6 \mathrm{rad} / \mathrm{s}$ equal to $30 \mathrm{~km} / \mathrm{h}$ vehicle speed under drag braking with an initial disc temperature of $20^{\circ} \mathrm{C}$. Tyre rolling radius was calculated from the tyre rolling circumference of the test car which was $1860 \mathrm{~mm}$, giving a tyre rolling radius of $0.29 \mathrm{~m}$. The value of heat transfer coefficient used was $90 \mathrm{~W} / \mathrm{m}^{2} \mathrm{~K}$ based on the experimental results [12]. The material properties of 3D model are shown in Table I.

The geometries of the ventilated disc and the prototype disc are given in Table II.

TABLE I: MATERIAL PROPERTIES OF DISC BRAKE COMPONENTS ADAPTED FROM DAY [8]

\begin{tabular}{|c|c|c|c|c|c|c|}
\hline Properties & 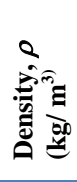 & 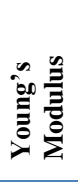 & 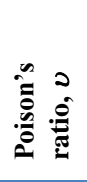 & 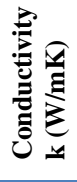 & 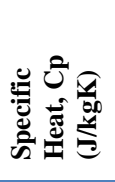 & 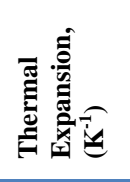 \\
\hline $\begin{array}{l}\text { Cast iron } \\
\text { (Brake disc) }\end{array}$ & 7050 & $\begin{array}{l}116 \\
\text { GPa }\end{array}$ & 0.27 & 53.3 & 550 & $11.0 \times 10^{-6}$ \\
\hline $\begin{array}{l}\text { Stainless steel } \\
\text { (Brake disc) }\end{array}$ & 7800 & $\begin{array}{l}200 \\
\mathrm{GPa}\end{array}$ & 0.29 & 25 & 460 & $11.0 \times 10^{-6}$ \\
\hline $\begin{array}{l}\text { NAO friction } \\
\text { material }\end{array}$ & 2620 & $\begin{array}{l}210 \\
\mathrm{MPa}\end{array}$ & 0.29 & 2.0 & 1100 & $16.1 \times 10^{-6}$ \\
\hline Backplate & 7850 & $\begin{array}{l}210 \\
\mathrm{GPa}\end{array}$ & 0.30 & 32.0 & 595 & - \\
\hline Piston & 7887 & $\begin{array}{l}210 \\
\text { GPa }\end{array}$ & 0.30 & 32.0 & 595 & - \\
\hline
\end{tabular}

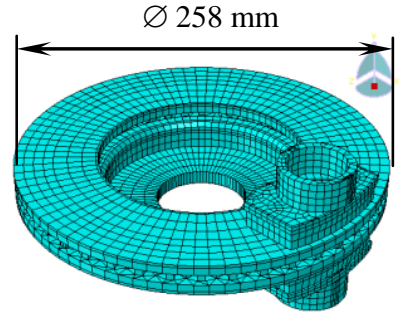

(a)

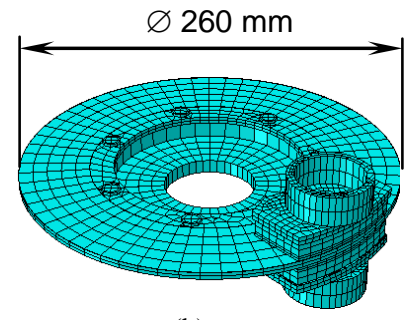

(b)
Fig. 1 (a). Standard ventilated disc (total mass is $5.71 \mathrm{~kg}$ ) (b) Prototype disc (total mass is $3.48 \mathrm{~kg}$ )

\begin{tabular}{llllll}
\multicolumn{5}{c}{ TABLE II: BRAKE DISC COMPARISON } \\
\hline & $\begin{array}{l}\text { Thickness } \\
(\mathrm{mm})\end{array}$ & $\begin{array}{l}\text { Disc } \\
\text { diameter } \\
(\mathrm{mm})\end{array}$ & $\begin{array}{l}\text { Effective } \\
\text { radius } \\
(\mathrm{mm})\end{array}$ & Friction & $\begin{array}{l}\text { Piston } \\
\text { diameter } \\
(\mathrm{mm})\end{array}$ \\
$\begin{array}{l}\text { Ventilated } \\
\text { disc }\end{array}$ & 22 & 258 & 101 & 0.41 & 50 \\
Solid disc & 4.9 & 260 & 104 & 0.37 & 50 \\
\hline
\end{tabular}

A FEA simulation of single stop braking was used to determine the effect of the vehicle mass on front brake temperatures in terms of temperatures and stresses. Equation (1) which describes the average heat flux density on each disc was derived based on average braking power over the disc friction area.

$$
\mathrm{q}=\frac{\mu p A_{p i s} r_{e f f} \omega}{A_{d}}
$$

\section{B. Vehicle Mass - Interface Temperature Analysis}

Temperatures during a single stop braking event were predicted for both discs using FEA simulations for the three different vehicle masses. Fig. 2 shows the predicted temperature profiles at a point on the rubbing surface which is at the disc mean radius $(70 \%$ duty level on prototype disc and $100 \%$ duty level on standard ventilated disc). The prototype disc shows the corresponding results where $30 \%$ of the braking energy has been absorbed by regenerative braking. A peak is seen at every revolution as the measurement point moves past the friction pad. In all cases, the ventilated discs remain cooler than the solid discs, by 
approximately $20^{\circ} \mathrm{C}$ at the end of the braking event. A comparison of (peak) temperatures at the end of the single stop braking event is shown in Fig. 5 the vehicle equipped with regenerative braking has a much reduced peak temperature compared with the standard ventilated disc without regenerative braking. This suggests that a lightweight brake disc could be used in a hybrid car even though the brake disc mass is reduced (from approximately $5.71 \mathrm{~kg}$ to $3.48 \mathrm{~kg}$ in the FE models).

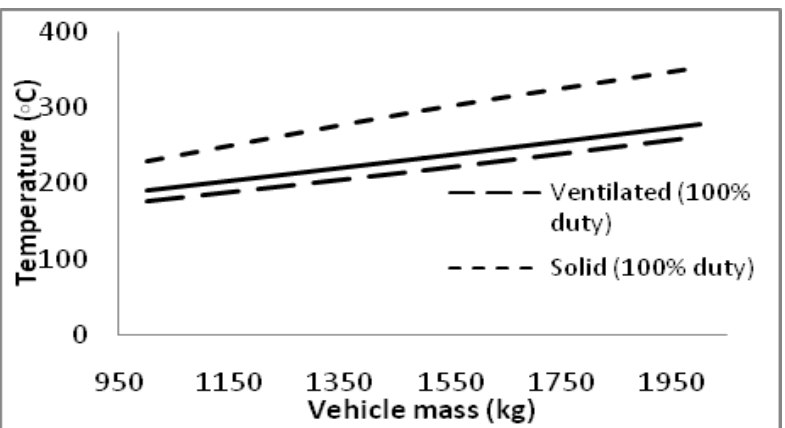

Fig. 2. Comparison of peak temperatures (after 4 seconds) at the end of the braking event between the standard ventilated disc, the prototype disc without $\mathrm{RB}$, and the prototype disc with $\mathrm{RB}$ for single stop braking.

\section{Lightweight Disc Brake - Temperature Distribution}

The conditions modelled were a single brake application from the vehicle maximum speed to zero speed, with a standard pad and piston assembly. For single stop braking, deceleration occurs in a very short time, so heat transfer from the disc to the hub could reasonably be neglected (Tirovic, 2008).

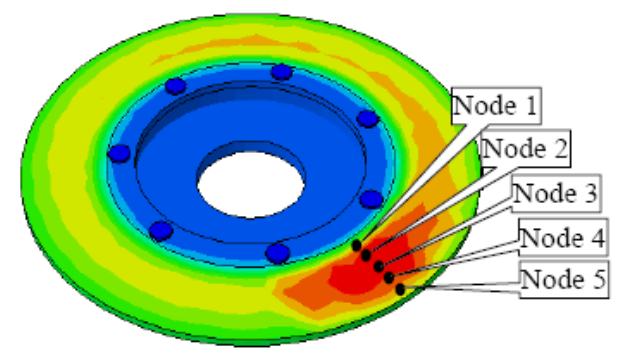

Fig. 3. FEA model of disc showing particular nodal positions

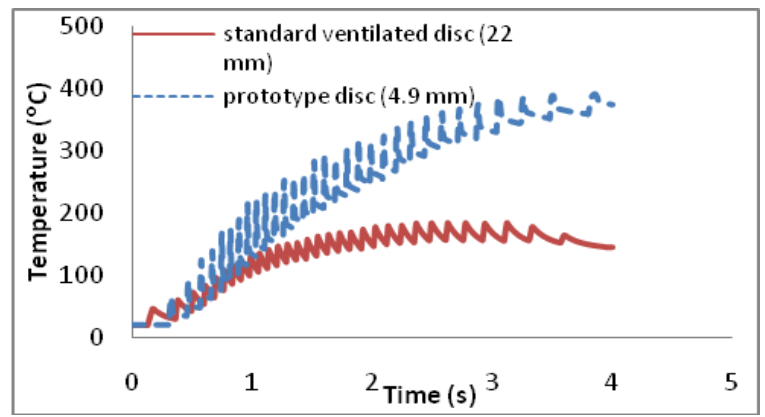

Fig. 4. Temperature profile between prototype (at node 3 ) and standard ventilated disc $\left(r_{e f f}\right)$

When a vehicle has a greater mass, more driver effort is required to decelerate at the same rate (Newton's lawMuhayen [13]). The results in Figure 5.6 show temperature profile for the prototype disc under single stop braking for different vehicle masses, which is important in selecting a lightweight disc design for regenerative braking.
The authors of the accepted manuscripts will be given a copyright form and the form should accompany your final submission.

\section{Thermal Stress Analysis}

Thermal stress was predicted from the temperature distribution during single stop braking. The predicted surface compressive stresses associated with the temperature rise can cause yielding in compression of the material in the disc surface because thermal stresses are much higher than purely mechanical stresses on the friction surface. The thermal stress on a disc surface at the disc effective radius is presented in Fig. 5-7 for comparison between different vehicle masses. It can be seen that high initial stresses at the friction surface follow from a high thermal gradient. Thermal stresses for the $2000 \mathrm{~kg}$ vehicle mass were close to $384 \mathrm{MPa}$, which can cause thermal fatigue cracks on the friction surface over time. Brake disc surface cracking only occurs when the thermal stress exceeds the yield stress of the material. Lower thermal stresses are predicted; $317 \mathrm{MPa}$ for $1500 \mathrm{~kg}$ and $262 \mathrm{MPa}$ for $1000 \mathrm{~kg}$ of vehicle mass. From these results, the discs show lower thermal stress than the maximum tensile stress of the disc material which is $910 \mathrm{MPa}$ [14]-[15].

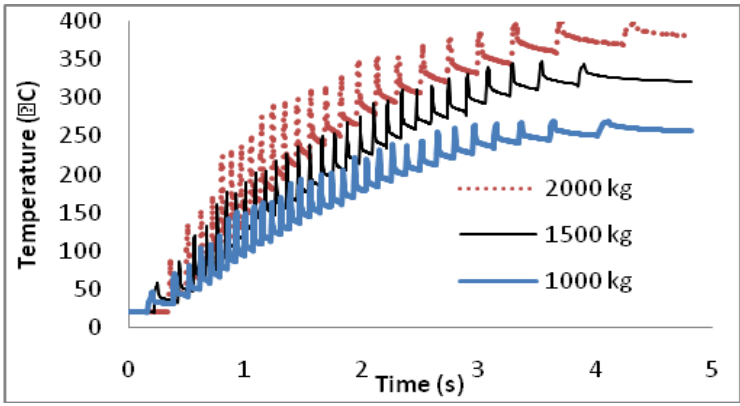

Fig. 5. Effect of different vehicle masses on disc temperature

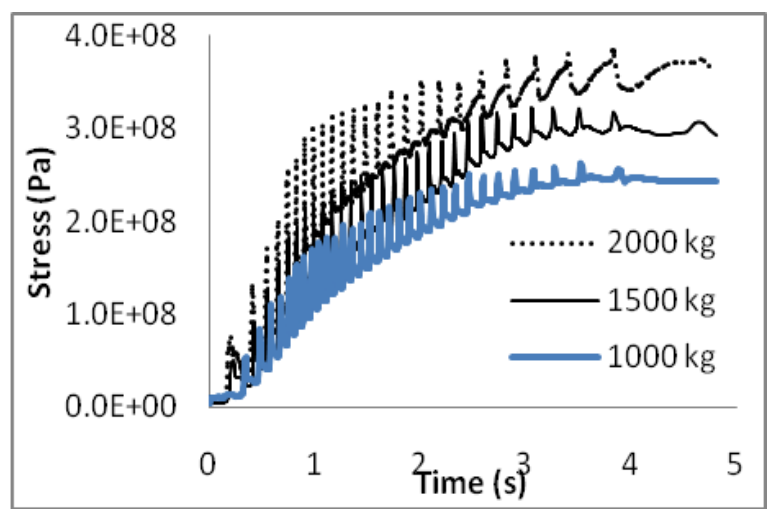

Fig. 6. Thermal stress profile on effective radius friction surface

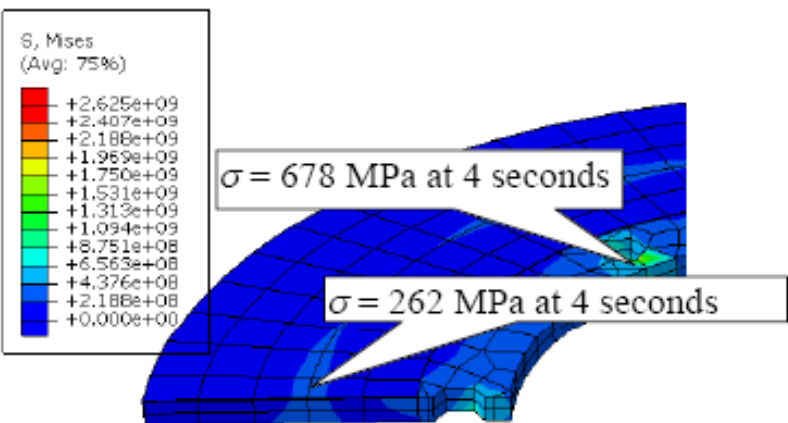

Fig. 7. Thermal and mechanical stress contour plot for the $1000 \mathrm{~kg}$ vehicle mass 


\section{E. Thermal Deformation}

Thermal deformation is primarily attributed to the thermal expansion of the disc and its constraint at the hub mounting face. The magnitude of the coning displacement was calculated from the thermal stress analysis throughout the simulated brake schedule. The conical deformation for the prototype disc was predicted at the disc's outside diameter and shows a wavy shape during braking with a maximum axial deformation of $380 \mu \mathrm{m}$. This is due to the uneven radial temperature distribution in the disc as the friction ring heats up and becomes hotter than the top hat section. The friction ring expansion is constrained by the bolts giving more stresses around the holes of the flat friction ring. This is the highly stressed area of the disc and must be carefully designed to avoid stress concentrators.

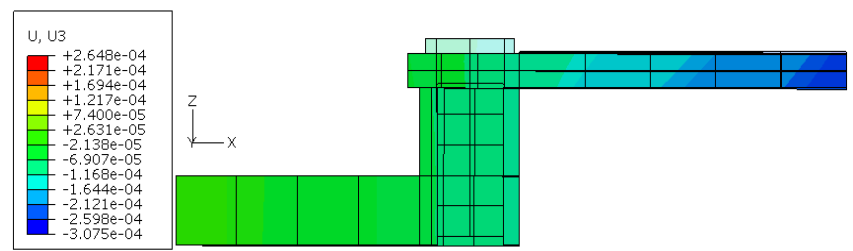

Fig. 8. Disc coning at the end of stop $(4 \mathrm{~s})$

\section{Single StOP AND DRAG BRAKING}

\section{A. Lightweight Disc Models}

Vehicle mass is a critical parameter for a lightweight brake disc design. It is necessary to complete thermal stress prediction under two conditions of usage i.e. single stop braking and drag braking for the models for the best solution of effective lightweight disc design. Eight solid disc models were designed based on a prototype disc concept and these were used in the analysis to study the relationship between disc weight, geometry and energy loading (vehicle mass and speed). The materials used in these models were cast iron and stainless steel. Each model was given a name e.g. Ss-A (Model A made of stainless steel), Gi-B (Model B made of cast iron), etc., and the geometries of the solid discs rotor are given in Fig. 9.

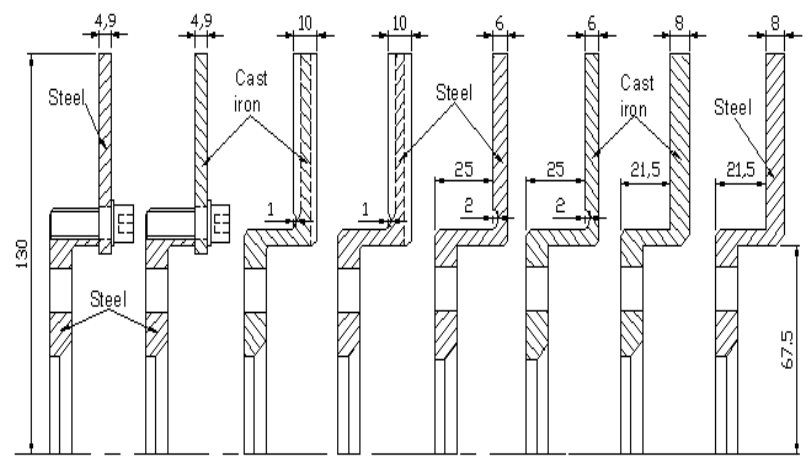

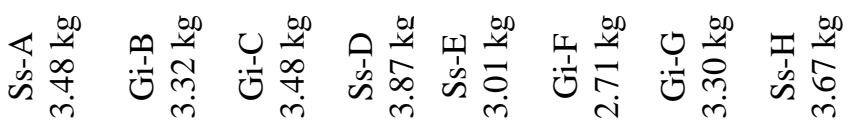

Fig. 9. Cross-section of the brake discs

\section{B. Analysis}

A fully coupled thermomechanical model was set up to predict the temperature changes of the brake disc shape caused by axial and radial deformation. Thermal conduction and convective heat transfer were the two modes of heat transfer considered. The convection heat transfer coefficient was $90 \mathrm{~W} / \mathrm{m}^{2} \mathrm{~K}$ over all exposed surfaces, and radiative heat transfer was considered negligible [12].

\section{Test 1 - Single-Stop Braking}
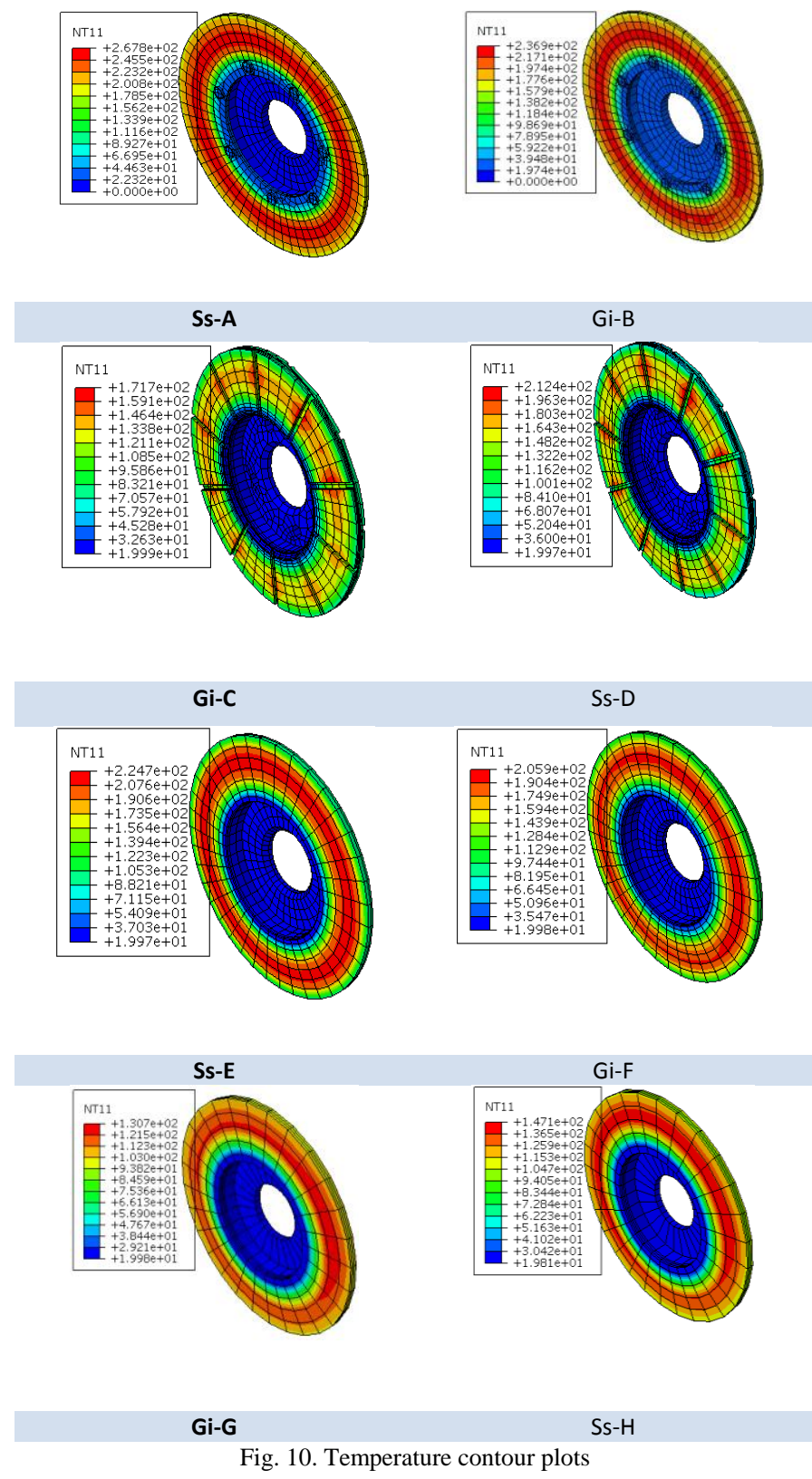

Braking power in a single stop brake was computed assuming no slip at the tyre/ground interface and that heat is generated at the friction interface of the brake. The models were analysed based on a minimum vehicle mass of $1000 \mathrm{~kg}$ to compare thermal stress results in medium conditions for single stop. Maximum surface temperatures were predicted at nodes on the disc, e.g. at the effective radius. Fig. 10 shows the temperature distributions predicted from the models. The lower temperatures predicted (below $200^{\circ} \mathrm{C}$ ) were on models Gi-C, Gi-G and Ss-H. Model Gi-C and Gi-G were made of 
cast iron, while model Ss-H, was made of stainless steel (Fig. 11). This shows that model Gi-G was the most suitable model in terms of low temperature rise, thermal stress and disc coning.

The comprehensive stresses associated with these temperature rises can cause yielding in compression of the material in the disc surfaces. Lower thermal stress, below 150 $\mathrm{MPa}$, was predicted on all except model Ss-A (Fig. 11). Higher values of thermal stress were considered acceptable in lower duty of braking, hence all models were analysed further. The deformation of the brake disc due to thermal loading is apparent when viewed through the disc cross section. The deformation of the brake disc region is primarily attributed to the thermal expansion of the disc. The magnitude of the coning displacement was calculated from the thermal stress analysis throughout the simulated brake schedule. Model Gi-C and Ss-D in Fig. 11(c) showed unacceptable thermal deformation. The result from a sensitivity study of thermal deflection with respect to the disc mass at the end of braking ( $4 \mathrm{~s}$ ) is shown in Fig. 4 for model Gi-F. Axial displacement (coning) was approximately 0.3 $\mathrm{mm}$. Overall coning prediction was between $0.17 \mathrm{~mm}$ to 0.38 $\mathrm{mm}$ for all models except the externally vented designs (model Gi-C and Ss-D) which had a greater axial displacement up to $1.22 \mathrm{~mm}$. Model Ss-E, Gi-F and Ss-H showed a small amount of axial displacement at the end of braking. Disc coning has to be reduced as well as reducing stresses to minimise disc cracking and instability of a lightweight disc. A further improvement to reduce disc coning is to create slot depth or undercut between friction ring and the hat should be considered. The reason for the undercut is to reduce the stiffness of the joint between the friction disc and the hat.
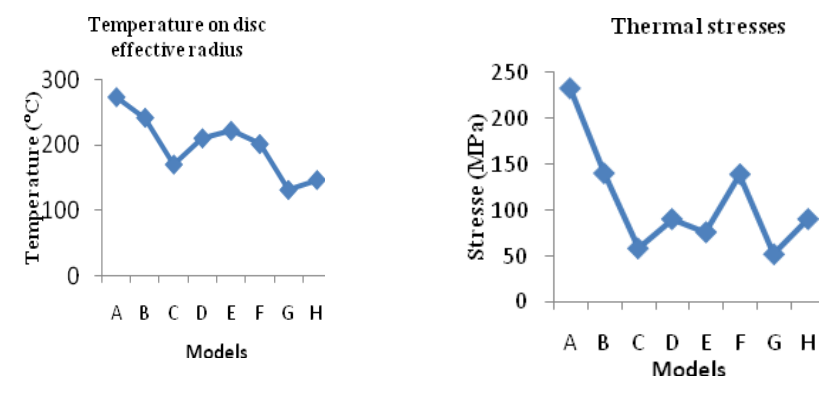

a) Maximum temperatures at 4 second of braking
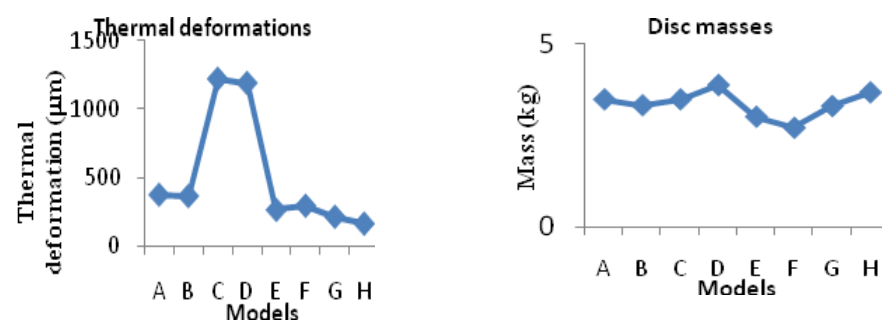

c) Thermal deformation at the end of braking d) Different disc masses between $2.71 \mathrm{~kg}$ to $3.87 \mathrm{~kg}$
Fig. 11. Single stop braking analysis

Maximum temperatures obtained from the thermomechanical analyses show the superiority of cast iron over stainless steel in reducing surface temperature and thermally induced stress (Fig. 11a and 11b). In order to absorb and transmit the heat generated at the friction interface, cast iron has a high volumetric heat capacity $\left(\rho \mathrm{C}_{\mathrm{p}}\right)$ and good thermal conductivity compared to stainless steel. Although stainless steel has a low coefficient of thermal expansion to minimise disc coning, it has higher density compared to cast iron.
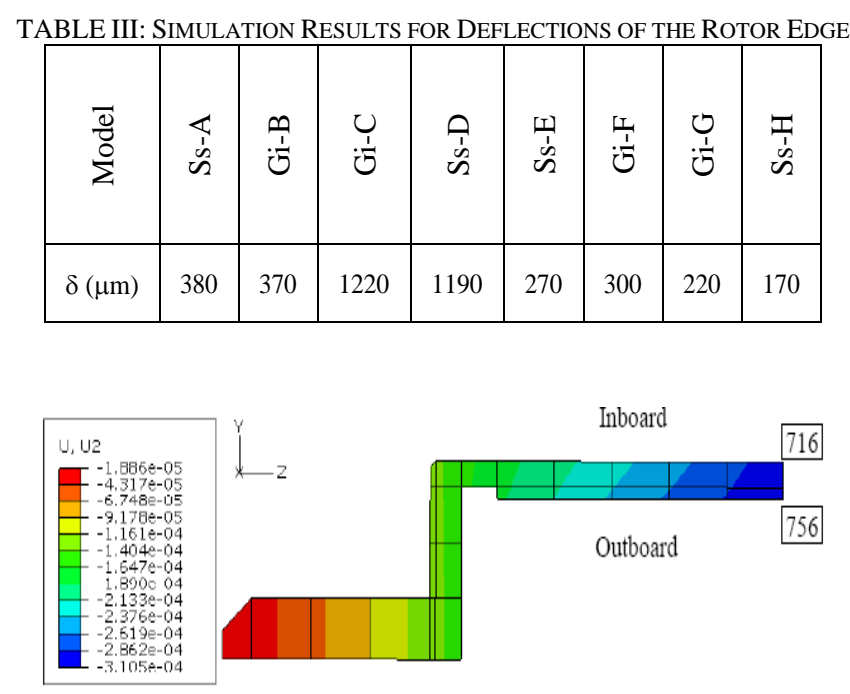

Fig. 12. Example of thermal deformation on model Gi-F in axial outboard direction.

Two models were proposed to replace model Gi-G. These were model Ss-E and Gi-F. Model Gi-F was made of cast iron and had good compressive strength, but at the same time it had low tensile strength as the material was brittle and prone to microcracking in tension. Model Ss-E was not practical to use in regenerative braking because of its weight i.e. model Gi-F, was more suitable to use in RBS because $30 \%$ of the energy is recuperated in the system and this will reduce thermal duty and hence temperature rise, thermal stress and thermal deformation during braking. From the thermomechanical analyses in single stop braking, a disc made of cast iron (which is the disc Gi-F) was selected as a design model for vehicle masses lower than $1500 \mathrm{~kg}$ that are equipped with regenerative braking.

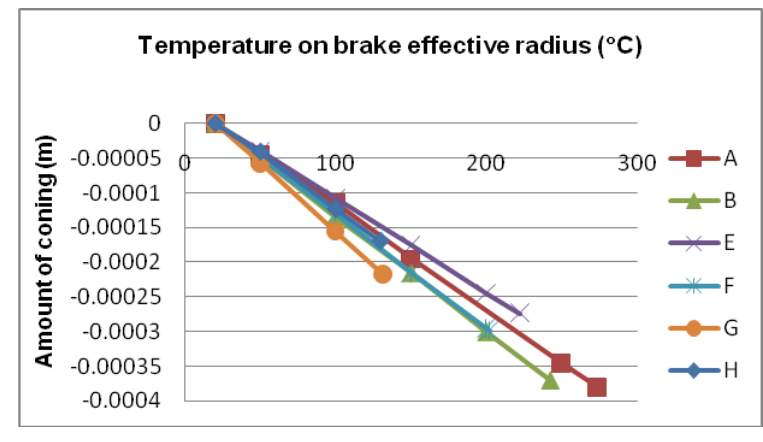

Fig. 13. Different amount of thermal coning between all models accept model Gi-C and Ss-D

Disc deflection was investigated for all models except models Gi-C and Ss-D as shown in Fig. 13. The results show negative values indicating that all models deformed in an 
axially outward direction. Model Ss-H had a disc thickness of $8 \mathrm{~mm}$ and was made of stainless steel, and this showed the least amount of thermal coning $(0.17 \mathrm{~mm})$ of most models but slightly more coning than model Ss-E when the temperature reached $50^{\circ} \mathrm{C}$. This clearly indicated the effect of the undercut on the friction disc and the "top hat" transition region. Models Gi-G and Ss-H (without undercut) revealed the largest amount of coning between temperatures of $50^{\circ} \mathrm{C}$ to $150^{\circ} \mathrm{C}$. Reducing the thermal coning of a brake disc needs an adequate amount of undercut between the transition ring/top hat. Model Ss-H has the lowest thermal coning, however this model was not further considered because it was too heavy with a mass of $3.67 \mathrm{~kg}$.

\section{Test 2 - Drag Braking}

Fig. 14 shows that model Gi-G with $8 \mathrm{~mm}$ of disc thickness shows a good analysis result in the thermomechanical analysis. The results also showed a similarity under single stop braking. Therefore model Gi-F was selected as the prototype lightweight disc because its mass was only $2.71 \mathrm{~kg}$. Model Gi-G was not suitable to use as a lightweight disc because it was heavy compared to model Gi-F.

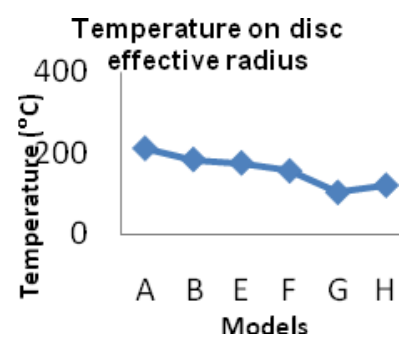

a) Maximum temperatures for 10 seconds of drag braking

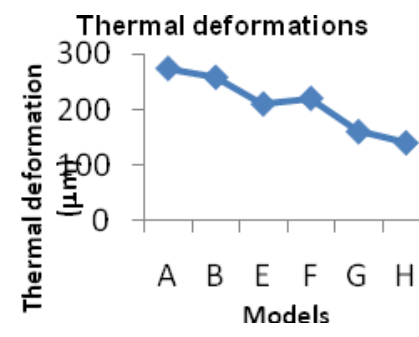

c) Thermal deformation at 10 seconds of drag braking

Fig. 14. Drag braking analysis

The total amount of disc coning is shown in Fig. 7. Although model Gi-G gives the second lowest disc coning compared to $\mathrm{Ss}-\mathrm{H}$, it shows faster time of axial deformation at $50^{\circ} \mathrm{C}$ (Fig. 7), which has the lowest disc coning. This is because disc Ss-H is made of stainless steel which has a higher tensile strength but lower thermal conductivity. Table III shows the thermal conductivity relationship between cast iron and stainless steel.

TABLE IV: MAXIMUM STRESSES AND CONDUCTIVITY. ADAPTED FROM GERE AND TIMOSHENKO [15]

\begin{tabular}{|l|c|c|}
\hline Discs & Min. Tensile Strength (MPa) & Conductivity (W/mK) \\
\hline Cast iron & 310 & 53.3 \\
\hline Stainless steel & 910 & 25.0 \\
\hline
\end{tabular}

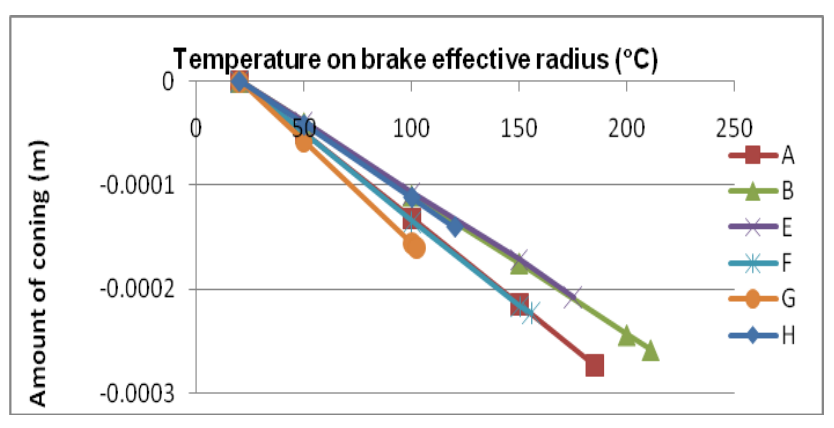

Fig. 15. Different amount of thermal coning between all models

\section{DISCUSSIONS}

The nearest designs to the prototype disc were Model Ss-A and Gi-B. From the thermal stress analysis, considering temperature predictions for Model Ss-A and Gi-B: both models showed high temperature rises at the disc effective radius for both test methods. The maximum temperatures were $274^{\circ} \mathrm{C}$ and $211^{\circ} \mathrm{C}$ for both discs. Using cast iron as the material, both test methods showed a lower value of temperature rise at $242^{\circ} \mathrm{C}$ and $183^{\circ} \mathrm{C}$, respectively. From the thermomechanical analysis investigation on the prototype disc, the maximum (permissible) operating temperature (MOT) was set to be $400^{\circ} \mathrm{C}$ for stainless steel. The MOT of cast iron also was set to the same value of $400^{\circ} \mathrm{C}$ to prevent the disc surface getting hotter. This means that maximum mass of the vehicle must be set below $1000 \mathrm{~kg}$ and maximum speed must be limited to a maximum of $80 \mathrm{~km} / \mathrm{h}$ for $4.9 \mathrm{~mm}$ disc thickness.

The maximum disc surface temperatures and thermal stresses for model Ss-C and Gi-D were predicted to have unacceptable values, in the form of very high temperature rise near the area of the external vents that is caused by the contact with the friction material. These designs were not analysed under drag braking because of the unacceptable axial thermal displacement. The brake disc flange remained substantially cooler than the friction surfaces, and radial expansion of the friction rings was restricted. Stresses were increased in the brake disc and conical deformation occurred in the brake disc flange. In addition, the brake disc surface temperatures were uneven so the disc became deformed unevenly (Fig. 11 (a) and 11 (b) ).

\section{CONCLUSION}

The design of the connection between the friction ring and the hub is important in a lightweight brake disc. The importance of this connection has been recognised and understood for many years [16] and car brake disc designers pay careful attention to the design of the so-called "top hat" region of the disc. Which friction face is mounted to the top hat, and the design of "undercut" both enable coning to be controlled within acceptable limits. However the lightweight brake disc of the type proposed here has a completely different temperature profile, both in terms of the magnitude of the temperatures reached during braking, and the distribution of temperature in the disc. This is also known from the use of lightweight discs on motorcycles but, again, 
the duty levels are much different. This work predicts the magnitude and distribution of temperature in a lightweight brake disc for a passenger car and consequently the expected coning. It therefore provides an indication of what design steps must be taken to keep coning to acceptable levels in operation.

It can be concluded that stainless steel is a suitable material for a lightweight brake disc in terms of mechanical and thermal strength, provided that the tribological characteristics are suitable (e.g. it might be advantageous to use different pad materials). Stainless steel is suitable to be used for disc thicknesses less than $8 \mathrm{~mm}$ because stainless steel has three times the tensile strength of cast iron (Table IV). For disc thicknesses of $8 \mathrm{~mm}$ or greater cast iron is suitable because of its high thermal conductivity and low Young's modulus, which limit the amount of disc damage caused by the heat flux generated by friction. When choosing the best disc material, aside from the properties which have been referred to in Table I, the heat capacity of the material has been shown to be as significant as the thermal conductivity. Disc material with higher heat capacity can decrease both the maximum surface temperature and the maximum stress applied to the disc surface. But stainless steel seems to be a good material for a lightweight disc, and it is better than Al-MMC because of its higher MOT. A disc made of stainless steel is designed to minimise stresses and distortion.

The contribution made by this research work to the field of vehicle braking is twofold. Firstly, the friction brakes can be downsized on a car with regenerative braking. Reducing the mass of the brake disc must consider temperatures, stresses, wear, deformation and durability. Second the example developed in this research illustrates that it is possible to reduce the brake disc mass by using a lightweight solid disc. The paper also presents a design approach for a lightweight brake disc based on mathematical and numerical (CAE) analysis with than associated experimental investigation.

\section{REFERENCES}

[1] Z. Zaini et al., "Mixed-mode braking for road vehicles with regenerative braking," in Proceedings of 6th European Conference on Braking, pp. $101-108,2010$.

[2] M. Ehsani et al., Modern electric, hybrid electric, and fuel cell vehicles: fundamentals, theory, and design, Second Editioned. New York: CRC Press, 2009.
[3] A. J. Day and T. P. Newcomb, "The dissipation of frictional energy from the interface of an annular disc brake," in Proceedings of the Institution of Mechanical Engineers, Part D: Transport Engineering 1984-1988, vol. 198, pp. 201-209, 1984.

[4] T. P. Newcomb, "Stopping revolutions: developments in the braking of cars from the earliest days," in Proceedings of the Institution of Mechanical Engineers 1847-1982, vol. 195, pp. 139 - 150, 1981.

[5] T. P. Newcomb and N. Millner, "Cooling rates of brake drums and discs," in Proceedings of the Institution of Mechanical Engineers, Automobile Division 1947-1970, vol. 180, pp. 191-205, 1965.

[6] A. J. Day et al., "A finite element approach to drum brake analysis," in Proceedings of the Institution of Mechanical Engineers 1847-1982, vol. 193, pp. 401-406, 1979.

[7] T. Hoffman and R. E. V. Druten, "Energy analysis of hybrid vehicle powertrains," presented at the conference of IEEE Int. Symp. Veh. Power Propulsion, 2004.

[8] A. J. Day, "Drum brake interface pressure distributions," in Proceedings of the Institution of Mechanical Engineers, Part D: Journal of Automobile Engineering 1989-1996, vol. 205, pp. 127-136, 1991.

[9] N. Fasci, "Legislation and type approval," Braking of Road Vehicles, 2008.

[10] C. M. Jefferson and R. H. Barnard, Hybrid Vehicle Propulsion, Southampton: WIT Press, 2002.

[11] R. Chicurel, "A compromise solution for energy recovery in vehicle braking," Elsevier Science Ltd, vol. 24, pp. 1029-1034, 1999.

[12] S. B. Sarip, "Lightweight friction brakes for a road vehicle with regenerative braking," Ph.D. Thesis, Engineering, Design and Technology, Bradford University, 2011.

[13] M. M. Muhayen, Vehicle Engineering, University of Bradford, Bradford, 2010.

[14] T. A. Philpot, Mechanic of Materials: An Integrated Leaning System: John Wiley \& Sons, Inc, 2007.

[15] J. M. Gere and S. P. Timoshenko, Mechanic of Materials, Stanley Thornes, 1999.

[16] T. Okamura and H. Yumoto, "Fundamental study on thermal behaviour of brake discs," SAE International, vol. 2006-01-3203, 2006.

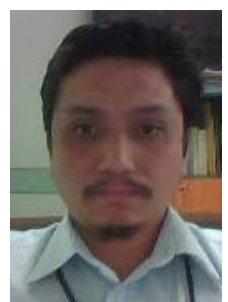

S. Sarip received the mechanical engineering degree from the Universiti Teknologi Malaysia, in 1998. Since 2000, he has been with the Department of Mechanical Engineering, Universiti Teknologi Malaysia Kuala Lumpur where he currently is an Senior Lecturer. His research interests include brake performance, regenerative braking, MR fluid brake, thermal comfort, design, ocean thermal energy and renewable energy systems. Dr. S. Sarip is a member of IACSIT, International Association of Engineers, SAE International, Board of Engineers Malaysia, and The Institution of Engineers, Malaysia. 